\title{
Self-Absorption of Neutron Capture Gamma-Rays in Gold Samples
}

\author{
K. Wisshak, G. Walter, F. Käppeler \\ Institut für Angewandte Kernphysik
}

\section{Kernforschungszentrum Karlsruhe}





\section{KERNFORSCHUNGSZENTRUM KARLSRUHE}

Institut für Angewandte Kernphysik

KfK 3542

Self-Absorption of Neutron Capture Gamma-Rays in Gold Samples

K. Wisshak, G. Walter, F. Käppeler

Kernforschungszentrum Karlsruhe $\mathrm{GmbH}$, Karlsruhe 
Als Manuskript vervielfältigt

Für diesen Bericht behalten wir uns alle Rechte vor

Kernforschungszentrum Karlsruhe $\mathrm{GmbH}$

ISSN 0303-4003 


\section{ABSTRACT}

The self absorption of neutron capture gamma rays in gold samples has been determined experimentally for two standard setups used in measurements of neutron capture cross sections. One makes use of an artificially collimated neutron beam and two $\mathrm{C}_{6} \mathrm{D}_{6}$ detectors, the other of kinematically collimated neutrons and three Moxon-Rae detectors. Correction factors for an actual measurement of a neutron capture cross section using a gold standard of $1 \mathrm{~mm}$ thickness up to $12 \%$ were found for the first setup while they are only $4 \%$ for the second setup. The present data allow to determine the correction in an actual measurement with an accuracy of $0.5-1 \%$.

\section{Zusammen fassung}

Selbstabsorption von Neutroneneinfang - Gammastrahlung in Goldproben

Die Selbstabsorption von Neutroneneinfang-Gammastrahlung in Goldproben wurde experimentell für zwei Anordnungen bestimmt, die zur Messung von Neutroneneinfangquerschnitten verwendet werden. Die eine benutzt einen künstlich kollimierten Neutronenstrahl und zwei $\mathrm{C}_{6} \mathrm{D}_{6}$ Detektoren, die andere kinematisch kollimierte Neutronen und drei Moxon-Rae Detektoren. Die Korrekturen in einer Messung des Neutroneneinfangquerschnittes mit einer $1 \mathrm{~mm}$ dicken Goldprobe als Standard betragen bis zu 12 o für den ersten Aufbau und nur etwa $4 \%$ für den zweiten. Die vorliegenden Meßdaten erlauben es, diese Korrekturfaktoren mit einer Genauigkeit von $0.5-1 \% \mathrm{zu}$ bestimmen. 


\section{INTRODUCTION}

In neutron capture cross section measurements often gold is used as a cross section standard. This is especially the case for measurements in the keV range if a Van de Graaff accelerator and the ${ }^{7} \mathrm{Li}(\mathrm{p}, \mathrm{n})$ reaction is used for neutron production (Refs. $\left.1,2,3,4\right)$. In such experiments normalization at thermal energies or by the saturated resonance method ${ }^{5}$ cannot be applied like in Linac experiments 6,7. Gold is favoured as a standard since this cross section is known with an accuracy of $\sim 2.5 \%$ (Ref. 8) and samples are monotopic and easily available.

In relative measurements many systematic uncertainties e.g. due to electronic drifts, detector bias, detector efficiency and multiple scattering cancels out to a large extent thus allowing for a higher accuracy. A disadvantage in using gold standards is the strong absorption of gamma-rays in the sample material due to its high density and $\mathrm{z}$-value. In particular, this holds for measurements with artificially collimated neutrons. Normally, in this type of set-up the sample is placed perpendicular to the neutron beam and the detectors are located at $90^{\circ}$ with respect to the beam axis. This means that the detectors are directed towards the edge of the samples where absorption is most severe. Accurate results, can therefore be obtained only, if they are corrected properly for this effect.

Exact numerical calculation of the gamma-ray self-absorption is difficult. This would require not only the detailed knowledge of the different absorption processes and the shape of the capture gamma-ray spectrum, but also the geometrical shape and the various absorption mechanisms of the detectors. One has to calculate the efficiency of the detector for each gamma-ray according to its energy, entrance angle and place where it is absorbed in the detector. Simple analytical calculations have been performed by Macklin ${ }^{9}$ but they can serve only as a rough estimate for this effect.

The aim of the present paper is to determine the gamma-ray self-absorption in gold experimentally by measuring neutron capture yields from samples of different thickness. This is done for two types of experimental setups, which were widely used over the last 
years for neutron capture cross section measurements $1,2,10-13$ :

a) The first setup makes use of an artificially collimated neutron beam produced at a Van de Graaff accelerator via the ${ }^{7} \mathrm{Li}(\mathrm{p}, \mathrm{n})$ reaction $2,12,13$. Two $\mathrm{C}_{6} \mathrm{D}_{6}$ detectors located at 90 deg with respect to the beam axis are detecting capture gamma-rays. The samples are placed at a flight path of $60 \mathrm{~cm}$ from the neutron target.

b) In the second case $1,10,11$ a kinematically collimated neutron beam is produced via the ${ }^{7} \mathrm{Li}(\mathrm{p}, \mathrm{n})$ reaction at proton energies just above the reaction threshold. Three Moxon-Rae detectors with different converter materials are used for the detection of capture events. The samples are located at a flight path of only 5-10 cm. The detectors are adjusted at a backward angle of 120 deg with respect to the beam axis, completely outside the neutron cone.

\section{EXPERIMENT}

a) Measurements with $\mathrm{C}_{6} \mathrm{D}_{6}$ Detectors

The measurements have been performed at the Karlsruhe pulsed 3 MV Van de Graaff-accelerator. Monoenergetic neutrons in the energy range $200 \pm 20 \mathrm{keV}$ were produced via the ${ }^{7} \mathrm{Li}(\mathrm{p}, \mathrm{n})$-reaction using a thin metallic lithium target. As the shape of the capture gamma-ray spectrum of gold does not change rapidly in the $\mathrm{keV}$ range 14 the self-absorption was supposed to be energy-independent and can therefore be determined at any energy. The energy of $200 \mathrm{keV}$ was chosen for the following reasons:

i) the neutron flux produced in the ${ }^{7} \mathrm{Li}(\mathrm{p}, \mathrm{n})$ reaction is still large;

ii) the capture cross section is sufficiently large to observe the capture events with good statistical accuracy;

iii) the correction for multiple scattering and selfshielding of neutrons in the sample is small;

iv) the use of quasi-monoenergetic neutrons offers very clean background conditions in the measured 


\section{spectra and thus reduces systematic uncertainties considerably.}

The experimental set-up which is shown schematically in Fig. 1 has been described in detail in Ref. 2. The neutron beam was collimated by a shielding of ${ }^{6} \mathrm{LiCO}_{3},{ }^{10} \mathrm{~B}$ and paraffin to a diameter slightly larger than the sample diameter. The samples are located perpendicular to the neutron beam at a flight path of $\sim 60 \mathrm{~cm}$. They are viewed by two $\mathrm{C}_{6} \mathrm{D}_{6}$ detectors at $90^{\circ}$ with respect to the neutron beam axis. The detectors (diameter $115 \mathrm{~mm}$, thickness $96 \mathrm{~mm}$ ) contained $\sim 11 \mathrm{NE} 230$ and the distance from their front window to the beam axis was $40 \mathrm{~mm}$. The gold samples with different thickness are fixed in a low mass sample changer and are cyclically brought into the measuring position. A ${ }^{6} \mathrm{Li}$ glass detector, located at $90^{\circ}$ to the beam direction at a distance of $45 \mathrm{~cm}$ from the neutron target, served as a neutron monitor. The count rate of this detector was used to normalize the spectra of the individual samples to the same neutron flux.

Spectra were taken from samples with 18 and $40 \mathrm{~mm}$ diameter, and various thicknesses. In addition we used a graphite sample and an empty position in the sample changer for background determination. Characteristic details of the samples are compiled in Table I. Data acquisition was performed in two-dimensional mode using 1024 time-of-flight channels and 16 pulse height channels for each detector. To demonstrate the experimental effect-to-background ratio, Fig. 2 shows the unweighted time-of-flight spectra which were obtained from the thinnest samples of each diameter (all pulse height channels of both detectors being added).

In data evaluation the following steps have been performed:

1.) The TOF spectra of both detectors (each pulse heigh group separately) were integrated between channels $A_{1}$ and $A_{2}$ in the region of the measured effect. The same was done between channels $B_{1}$ and $B_{2}$ on the right hand side of the gamma-ray peak in order to obtain the time-independent background. The respective counting rates of both detectors are added. 
2.) The time-independent background was subtracted in each pulse height group, the remaining effect multiplied with the corresponding value of the weighting function, and then the results of the individual groups were added. In this way a pulse height weighted count rate $C_{i}$ was obtained for each sample.

3.) The values $C_{i}$ were normalized to equal neutron fluences via the count rates of the neutron flux monitor.

4.) As no difference was observed in the data taken with the graphite scattering sample and without any sample, both count rates $\mathrm{C}_{\text {graphit }}$ and $\mathrm{C}_{\text {empty }}$ were averaged and then substracted as a time-dependent background from the count rates $\mathrm{C}_{\text {gold }}$ of the individual gold samples. After this background correction the result was divided by the sample mass and the multiple scattering and resonance self-shielding correction MS (See Table I) which was calculated with the SESH code of Fröhner ${ }^{15}$. The result is the relative neutron capture count rate per gramm of gold for different sample thickness.

5.) To obtain the correction for gamma-ray self-absorption, SA, an exponential function $S A=\exp (-a d)$ with $d$ being the sample thickness in mm was fitted to the values obtained after step 4 . These data were normalized by adjusting the function to yield $S A=1$ for sample thickness zero.

This procedure was performed twice using different TOF intervals between $A_{1}$ and $A_{2}$ as well as between $B_{1}$ and $B_{2}$ for the determination of effect and background. The difference between both evaluations was found to be well within the statistical uncertainties.

b) Measurements with the Moxon-Rae detectors

A kinematically collimated neutron beam is produced via the $7_{\mathrm{Li}}(\mathrm{p}, \mathrm{n})$ reaction by chosing the proton energy $20 \mathrm{keV}$ above the reaction threshold. In this way a continuous neutron spectrum in the energy range from 10 to $90 \mathrm{keV}$ is obtained. The opening angle of the neutron cone is $90 \mathrm{deg}$. No further collimation is 
required and flight paths as short as 5 to $10 \mathrm{~cm}$ can be used in the experiments. The capture events are observed by detectors placed at backward angles completely outside the neutron cone. Details of the experimental method have been described in Refs.1,16. A schematic view of the setup is shown in Fig. 3. Three Moxon-Rae detectors with graphite, bismuth-graphite and bismuth converters, respectively, were used to detect the capture events. The samples were located at a flight path of $8 \mathrm{~cm}$, the distance from sample to detector was $16 \mathrm{~cm}$ and the angle between beam and detector axis $120 \mathrm{deg}$. Two ${ }^{6} \mathrm{Li}$ glass detectors at 0 deg and 20 deg served as neutron flux monitors.

Time of flight spectra were taken from the same samples as were used in the $\mathrm{C}_{6} \mathrm{D}_{6}$-experiment. The signal to background ratio is demonstrated in Fig. 4 showing the TOF spectra as measured with the thinnest samples used for each diameter. Due to the short flight path the neutron flux is much higher at the sample position compared to the $\mathrm{C}_{6} \mathrm{D}_{6}$ measurements. Consequently a much better signal to background ratio and statistical accuracy was obtained. In the background spectrum the $35.4 \mathrm{keV}$ resonance from capture in the aluminium frame of the sample changer shows up.

The data evaluation comprised the following steps:

1.) All TOF spectra were transformed to a common average flight path. This was necessary as the flight paths of the individual samples varied by $\pm 0.3 \mathrm{~mm}$. The transformation accounts for the different time scale and solid angle of the individual samples.

2.) The TOF spectra were normalized to equal neutron fluence using the data as measured with the neutron flux monitors. The resulting correction factors were always less than $0.6 \%$

3.) The background was subtracted. In the time region used for the present evaluation, no differences were observed in the spectra measured with the graphite sample and without sample. Therefore both spectra were added in order to improve statistics. 
4.) The background corrected counting rate was integrated in the region from $A_{1}$ to $A_{2}$ (see Fig. 4) where the signal to background ratio is large. This corresponds to an energy intervall of $60 \pm 8 \mathrm{keV}$. The counting rate was divided by the sample mass and the multiple scattering correction MS (See Table I).

5.) This step was the same as described for the $\mathrm{C}_{6}{ }^{\mathrm{D}} 6$ measurements.

The analysis was performed for the data taken with each detector, separately, but also for the summed spectra of all detectors.

III. RESULTS

a) Measurements with the $\mathrm{C}_{6} \mathrm{D}_{6}$ detectors

In Table II the results for gamma-ray self-absorption SA as measured with the $\mathrm{C}_{6} \mathrm{D}_{6}$ detectors are compiled. The quoted systematic uncertainty consists of $0.5 \%$ for the multiple scattering correction and $0.5 \%$ for the normalization to equal neutron flux. The flight path was $609 \mathrm{~mm}$ and differed by less than $\pm 0.7 \mathrm{~mm}$ for the individual samples. Therefore the corresponding systematic uncertainty was neglected. The experimental points and the fitted exponential functions are plotted in Fig. 5. In any actual measurement the counting rates of the gold sample has to be divided by the respective value of $S A$ in order to correct properly for the gamma-ray self-absorption in the sample.

From the results given in Table II and Fig. 5 the following conclusions can be drawn:

1.) Gamma-ray self-absorption may cause severe corrections if gold samples of $\sim 0.5-1 \mathrm{~mm}$ thickness are used as standards in relative cross section measurements.

2.) The gamma-ray self absorption of gold samples with constant radius can be well described by an exponential law. This allows to estimate the self-absorption for other sample materials. 
3.) The exponent of the exponential law is in good approximation proportional to the sample radius. This allows for an easy interpolation to samples with other radii.

4.) The present data can be used to determine the respective correction for an actual measurement with an accuracy of $\sim 1 \%$

The present data are exactly valid for the geometrical arrangement and detector size used in our setup. They can also be used, however, to estimate the effect for other experiments. In addition, they can serve as a test of all codes for calculating such corrections. It has to be mentioned that these rather large values for SA have been measured with a relatively short distance between detector and beam axis. As the correction will increase with increasing distance between detector and sample this distance should always be chosen as close as possible.

b) Measurements with the Moxon-Rae Detectors

In Table III the results for SA are compiled as measured with Moxon-Rae detectors for various converter materials. The quoted systematic uncertainty of $0.7 \%$ is composed of the following parts: uncertainty in flight path $0.3 \%$; normalization to equal neutron fluence $0.3 \%$; multiple scattering $0.5 \%$. In Fig. 6 the results as obtained from the summed spectra of all three detectors are plotted.

The results given in Table III and Fig. 6 allow for the following conclusions:

1.) The correction for gamma-ray self-absorption is less pronounced for this setup compared to the setup using $C_{6}{ }^{D} 6$ detectors because the detectors are located at a backward angle of 120 deg with respect to the beam axis and not at 90 deg.

2.) The self-absorption is well described by the exponential law as in the measurements with $\mathrm{C}_{6} \mathrm{D}_{6}$ detectors.

3.) In this geometry SA does not depend on the sample diameter. 
4.) The exponent a in the function SA(d) depends slightly on the converter material. This is well explained by their different efficiencies at low gamma-ray energies which is relatively high for the graphite and small for the bismuth converter. As the self-absorption occurs mainly in the intense soft component of the gold capture gamma-ray spectrum, the graphite converter shows the largest effect.

5.) The present data can be used to determine the self absorption correction for an actual experiment with an accuracy of $\sim 0.5 \%$.

In previous work ${ }^{1,11}$ SA simply was calculated according to the formula for a line sample ${ }^{17}$ :

$$
S A=\frac{1}{2 \mu a}\left(1-e^{-2 \mu a}\right)
$$

$\mu=$ total energy absorption coefficient

$2 \mathrm{a}=$ effective sample thickness.

The values for $\mu$ were taken from Ref. 18 averaged over the energy range from 1 to $6 \mathrm{MeV}$. The effective sample thickness was taken a factor of two larger than the geometrical thickness as the detector is placed at an angle of 120 deg with respect to the beam axis. In this way $\mathrm{SA}=0.96$ and $\mathrm{SA}=0.988$ was obtained for thickness of $\mathrm{d}=1 \mathrm{~mm}$ and $0.25 \mathrm{~mm}$, respectively. The present measurements proved that this simple procedure was surprisingly correct. However, one has to keep in mind, that the present measurements allow to deduce much more reliable correction factors. 


\section{REFERENCES}

1.) K. WISSHAK and F. KÄPPELER, Nucl. Sci.Eng. 77, 58 (1981)

2.) F. KÄPPELER, K. WISSHAK and L.D. HONG, NuCl.Sci.Eng. in print

3.) W.P. POENITZ, Nuc1. Sci. Eng. 57, 300 (1975)

4.) B.J. ALLEN, D.D. COHEN, and F.Z. COMPANY, J. Physics G 61173 (1980)

5.) R.L. MACKLIN, J. HALPERIN and R.R. WINTERS, Nucl. Instrum. Methods 164, 213 (1979)

6.) H. BEER, R.L. MACKLIN, Phys. Rev. C. 26, 1404 (1982)

7.) R.L. MACKLIN, Nucl. Sci. Eng. 81, 520 (1982)

8.) R.L. MACKLIN, J. HALPERIN and R.R. WINTERS, Phys. Rev. C 11, 1270 (1975)

9.) R.L. MACKLIN, private communications 1982

10.) K. WISSHAK and F. KÄPPELER, Nucl. Sci. Eng. 66363 (1978)

11.) K. WISSHAK and F. KÄPPELER, Nucl. Sci. Eng. 76, 148 (1980)

12.) J. ALMEIDA and F. KÄPPELER, Ap. J. 265, 417 (1983)

13.) B. LEUGERS, "Die Neutroneneinfangquerschnitte der Kryptonisotope und ihre Bedeutung für die Astrophysik", KfK 2895, Kernforschungszentrum Karlsruhe (1979)

14.) G. REFFO, F. FABBRI, K. WISSHAK and F. KÄPPELER, Nuc1. Sci. Eng. 80, 630 (1982)

15.) F.H. FRÖHNER, "SESH - A FORTRAN IV Code for Calculating the Self-Shielding and Multiple Scattering Effects for Neutron Cross Section Data Interpretation in the Unresolved Resonance Region", GA-8380 Gulf General Atomic Company (1968)

16.) K. WISSHAK, F. KÄPPELER, G. REFFO and F. FABBRI, Nucl. Sci. Eng., submitted for publication

17.) W.R. DIXON, Nucleonics $\underline{8}, 69$ (1951)

18.) E. STORM and H.I. ISRAEL, Nucl. Data Tables A 7, 565 (1970) 


$\begin{array}{ccc}\text { Sample Number Sample weight } & \text { Thickness } & \text { Thickness } \\ (\mathrm{g}) & (\mathrm{mm}) & (\mathrm{A} / \mathrm{b}) \\ & \times 10^{-3}\end{array}$

Correction for Multiple

Scatterino and Self-

shielding

$200 \mathrm{keV}$
$\mathrm{MS}$$\underset{\mathrm{MS}}{60 \mathrm{keV}}$

Measurement 1: Sample diameter $18 \mathrm{~mm}$

$\begin{array}{lllllll}1 & \mathrm{Au} & 1.508 & 0.31 & 1.811 & 1.021 & 1.029 \\ 2 & \mathrm{Au} & 2.902 & 0.59 & 3.486 & 1.034 & 1.048 \\ 3 & \mathrm{Au} & 4.749 & 0.97 & 5.705 & 1.046 & 1.061 \\ 4 & \mathrm{Au} & 7.314 & 1.49 & 8.786 & 1.060 & 1.072 \\ 5 & \text { Grafit } & 0.669 & 1.0 & 13.194 & - & - \\ 6 & \text { no } & - & - & - & - & -\end{array}$

Measurement 2: Sample diameter $40 \mathrm{~mm}$

\begin{tabular}{llcllll}
1 & Au & 2.948 & 0.12 & 0.717 & 1.010 & 1.014 \\
2 & Au & 4.561 & 0.19 & 1.110 & 1.015 & 1.022 \\
3 & Au & 7.086 & 0.29 & 1.724 & 1.023 & 1.034 \\
4 & Au & 11.508 & 0.47 & 2.800 & 1.031 & 1.050 \\
5 & Au & 23.459 & 0.97 & 5.707 & 1.059 & -076 \\
6 & Grafit & 1.729 & 0.5 & 6.905 & - & - \\
7 & no & - & - & - & - & 1.07 \\
\hline
\end{tabular}


Table II Correction for Gamma-Ray Self-Absorption SA as measured with the $\mathrm{C}_{6}{ }^{\mathrm{D}} 6$ detectors

\begin{tabular}{|c|c|c|}
\hline Sample & $\begin{array}{l}\text { Thickness } d \\
(\mathrm{~mm})\end{array}$ & $\begin{array}{c}\text { Correction for } \\
\text { Gamma-Ray Self- } \\
\text { Absorption } \\
\text { SA }\end{array}$ \\
\hline
\end{tabular}

Uncertainty

(\%)

$\mathrm{SA}$

$\begin{array}{cl}\text { statis- } & \text { syste- } \\ \text { tical } & \text { matic }\end{array}$ total

Measurement 1: Sample diameter $18 \mathrm{~mm}$
0.307
0.993
0.590
0.947
0.966
0.933
1.488
0.912
1.8
0.7
1.9
1.1
1.0
0.7
0.7
1.3
0.7
0.7
1.2
1.0

fitted exponent: $\quad a=0.066$

Measurement 2: Sample diameter $40 \mathrm{~mm}$
0.121
0.990
0.188
0.977
0.292
0.963
1.1
0.7
$1 \cdot 3$
0.474
0.940
0.8
0.7
1.1
0.966
0.891
0.6
0.7
1.1
0.7
0.4
0.7
0.9
0.8

fitted exponent: $a=0.122$ 
Table III Correction for Gamma-Ray Self-Absorption SA as measured with the Moxon-Rae Detectors a.

\begin{tabular}{|c|c|c|c|c|}
\hline \multirow{2}{*}{$\begin{array}{c}\text { Sample Thickness } \\
\text { d(mm) }\end{array}$} & \multicolumn{4}{|c|}{ Correction for Gamma-Ray Self-Absorption } \\
\hline & $\begin{array}{l}\text { Graphite } \\
\text { Converter }\end{array}$ & $\begin{array}{c}\text { Bismuth Graphite } \\
\text { Converter }\end{array}$ & $\begin{array}{l}\text { Bismuth } \\
\text { Converter }\end{array}$ & $\begin{array}{l}\text { Sum of all } \\
\text { Detectors }\end{array}$ \\
\hline ment 1: & ample diame & $18 \mathrm{~mm}$ & & \\
\hline $\begin{array}{l}0.307 \\
0.590 \\
0.966 \\
1.488\end{array}$ & $\begin{array}{l}0.987(0.99) \\
0.961(0.63) \\
0.958(0.65) \\
0.929(0.51)\end{array}$ & $\begin{array}{l}0.984(1.09) \\
0.983(0.68) \\
0.959(0.72) \\
0.941(0.55)\end{array}$ & $\begin{array}{l}0.993(0.98) \\
0.979(0.61) \\
0.970(0.63) \\
0.956(0.49)\end{array}$ & $\begin{array}{l}0.989(0.59) \\
0.974(0.37) \\
0.962(0.38) \\
0.941(0.30)\end{array}$ \\
\hline
\end{tabular}

Measurement 2: Sample diameter $40 \mathrm{~mm}$

$\begin{array}{lllll}0.121 & 0.997(0.74) & 0.995(0.81) & 0.999(0.72) & 0.997(0.44) \\ 0.188 & 0.992(0.56) & 0.994(0.61) & 0.993(0.55) & 0.993(0.33) \\ 0.292 & 0.984(0.62) & 0.987(0.66) & 0.995(0.59) & 0.989(0.36) \\ 0.474 & 0.978(0.46) & 0.979(0.50) & 0.989(0.44) & 0.982(0.27) \\ 0.966 & 0.958(0.31) & 0.960(0.34) & 0.978(0.29) & 0.966(0.18)\end{array}$

Fitted exponent:
$a=0.052$
$a=0.041$

$\mathrm{a}=0.031$

$a=0.041$

a) The statistical uncertainly in $\%$ is given in brackets.

The systematic uncertainty is $0.7 \%$. 
FIGURE CAPTIONS

Fig. 1 Schematic view of the experimental setup for measurements of neutron capture cross sections using an artificially collimated neutron beam and two $\mathrm{C}_{6} \mathrm{D}_{6}$ detectors for the detection of neutron capture gamma rays. The neutron energy is determined via the flight time from neutron target to the sample.

Fig. 2 Time of flight spectra as measured with the $\mathrm{C}_{6} \mathrm{D}_{6}$ detectors and the thinnest samples of $20 \mathrm{~mm}$ and $9 \mathrm{~mm}$ radius, respectively. (AIl pulse height channels of both detectors are added) The position of the prompt gamma ray peak represents the zero point of the time of flight measurement and the flight time is increasing to the left.

Fig. 3 Schematic view of the experimental setup for measurements of neutron capture cross sections using an kinematically collimated neutron beam and three Moxon-Rae detectors for the detection of neutron capture gamma rays.

Figs.4a,b Time of flight spectra as measured with the Moxon-Rae detectors and the thinnest samples of $20 \mathrm{~mm}$ and $9 \mathrm{~mm}$ radius, respectively (summed spectra of all detectors) and the respective background as measured without sample.

Fig. 5 Neutron capture gamma-ray self-absorption SA in gold samples with two different diameters in dependence from the sample thickness. The measurements have been performed using the setup shown in Fig. 1.

Fig. 6 Neutron capture gamma-ray self-absorption SA in gold samples with two different diameters in dependence from the sample thickness. The measurements have been performed using the setup shown in Fig. 3 . 


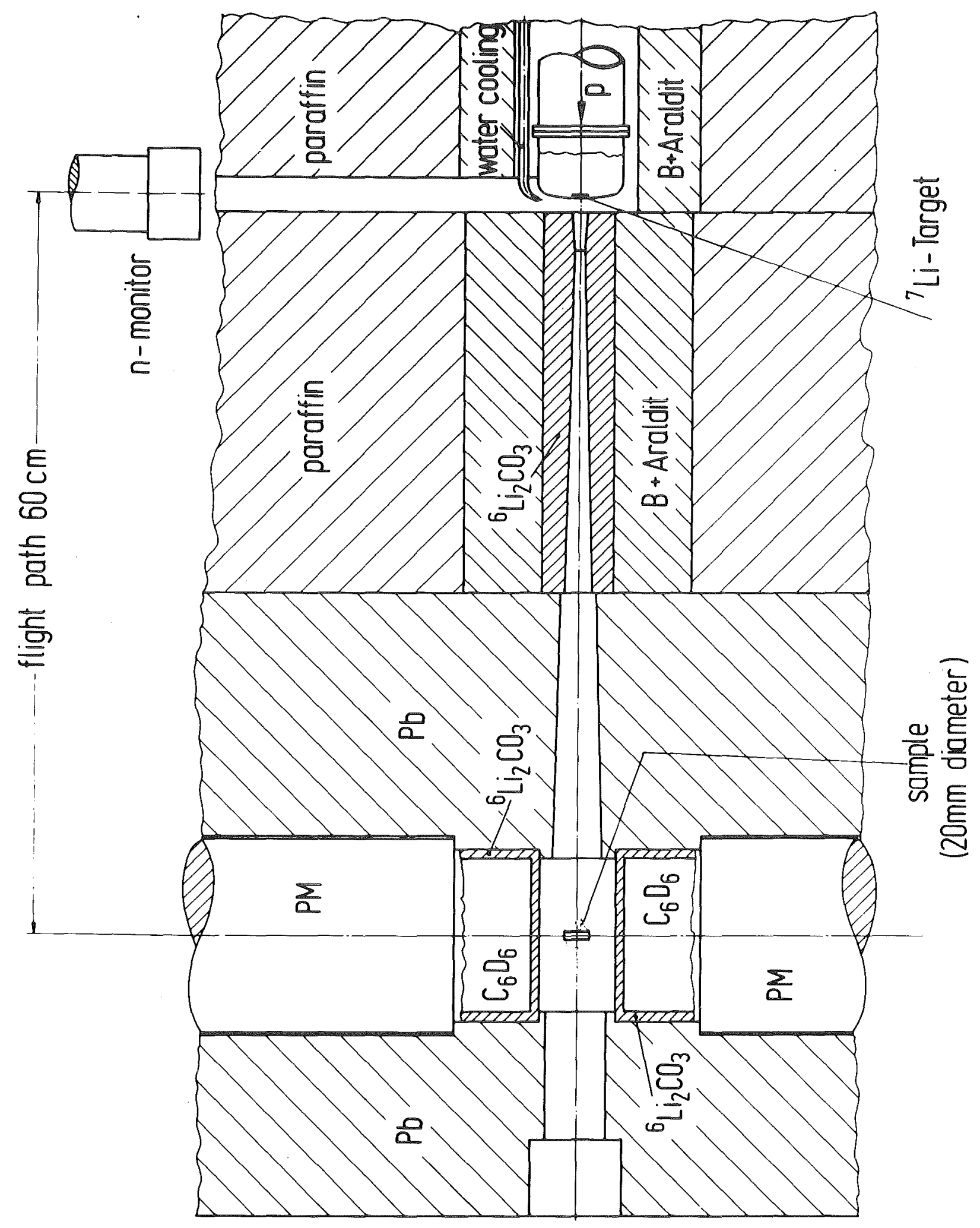

Fig. 1 


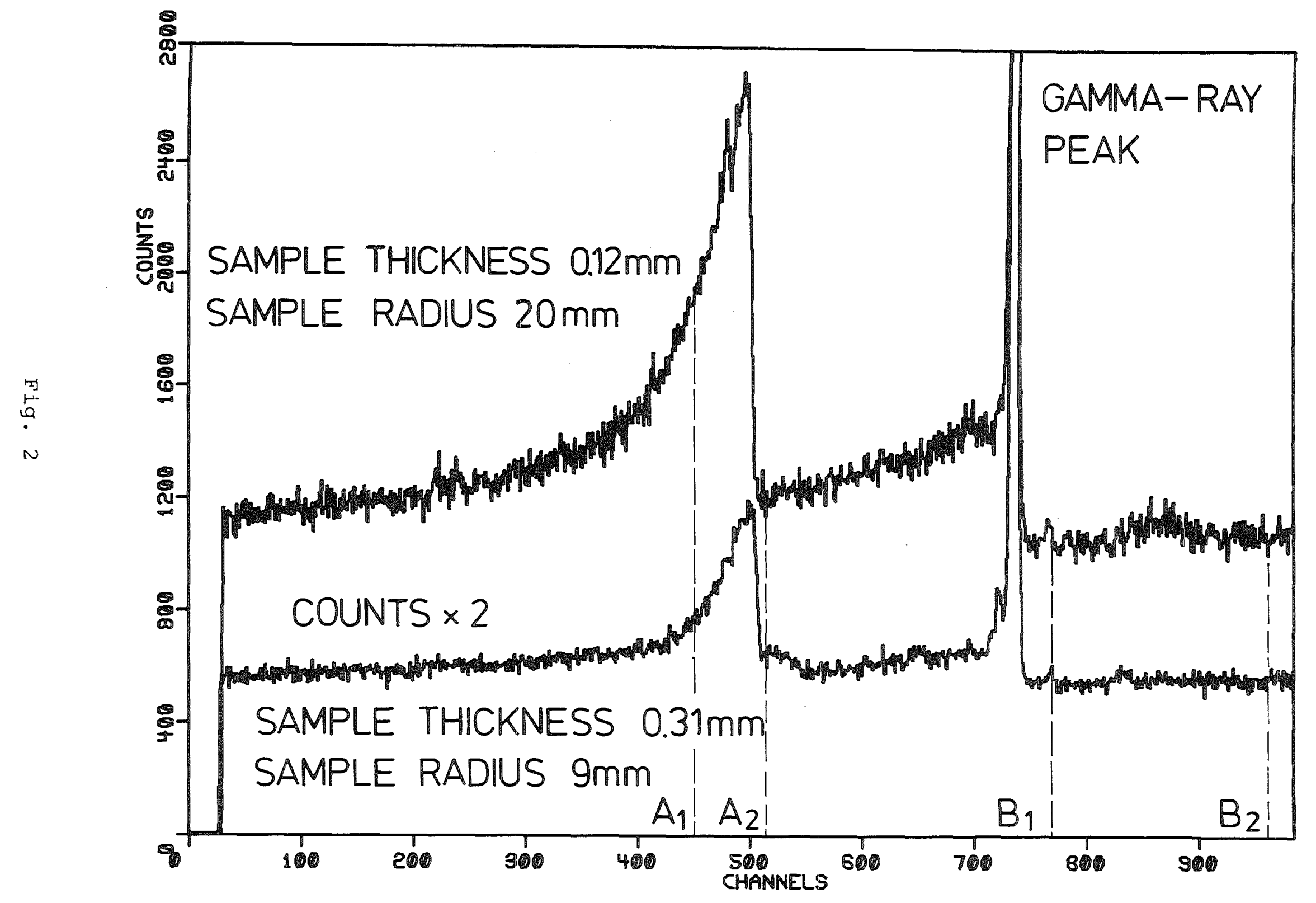


(at $O \mathrm{deg}, 93,5 \mathrm{~cm}$ flight path )

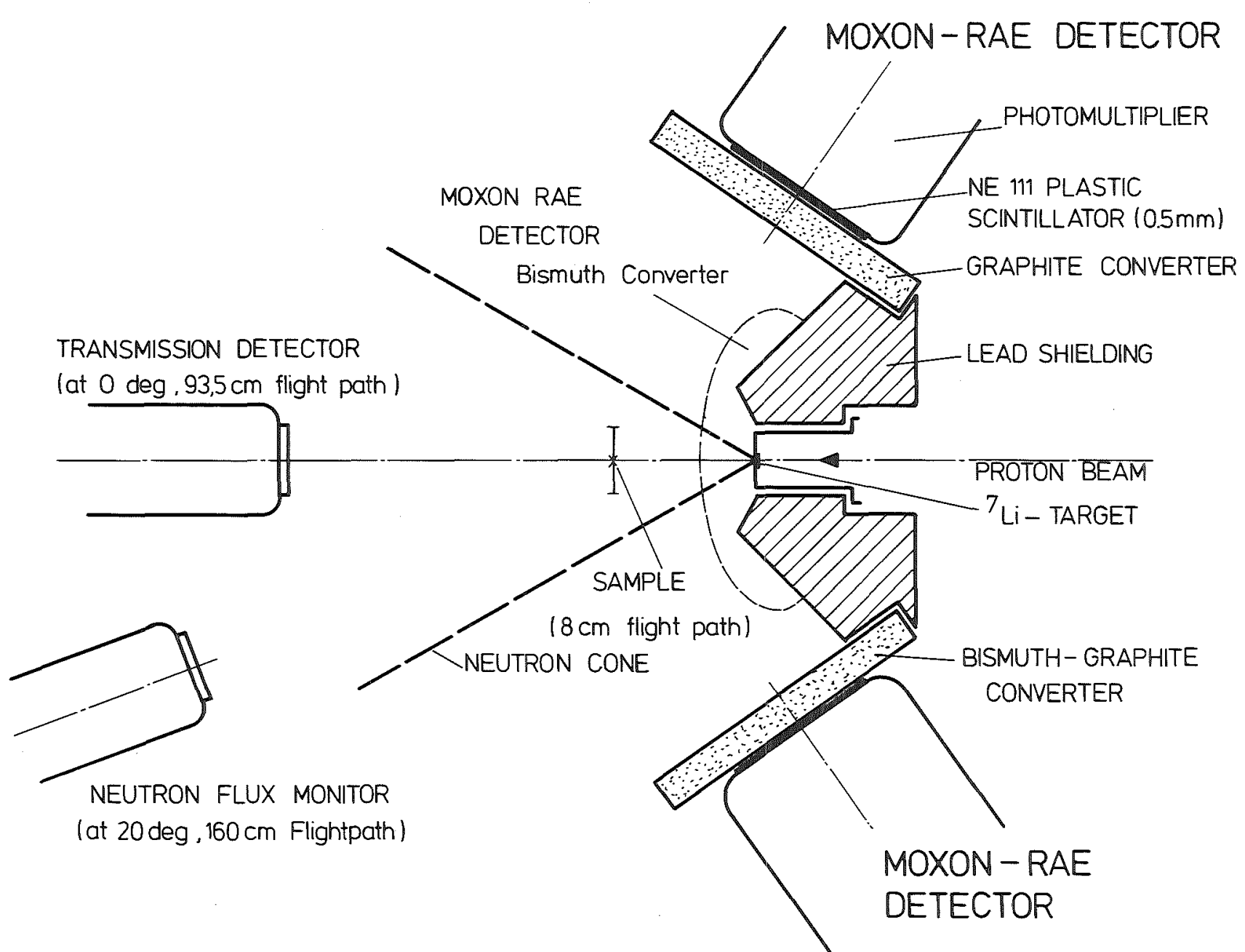




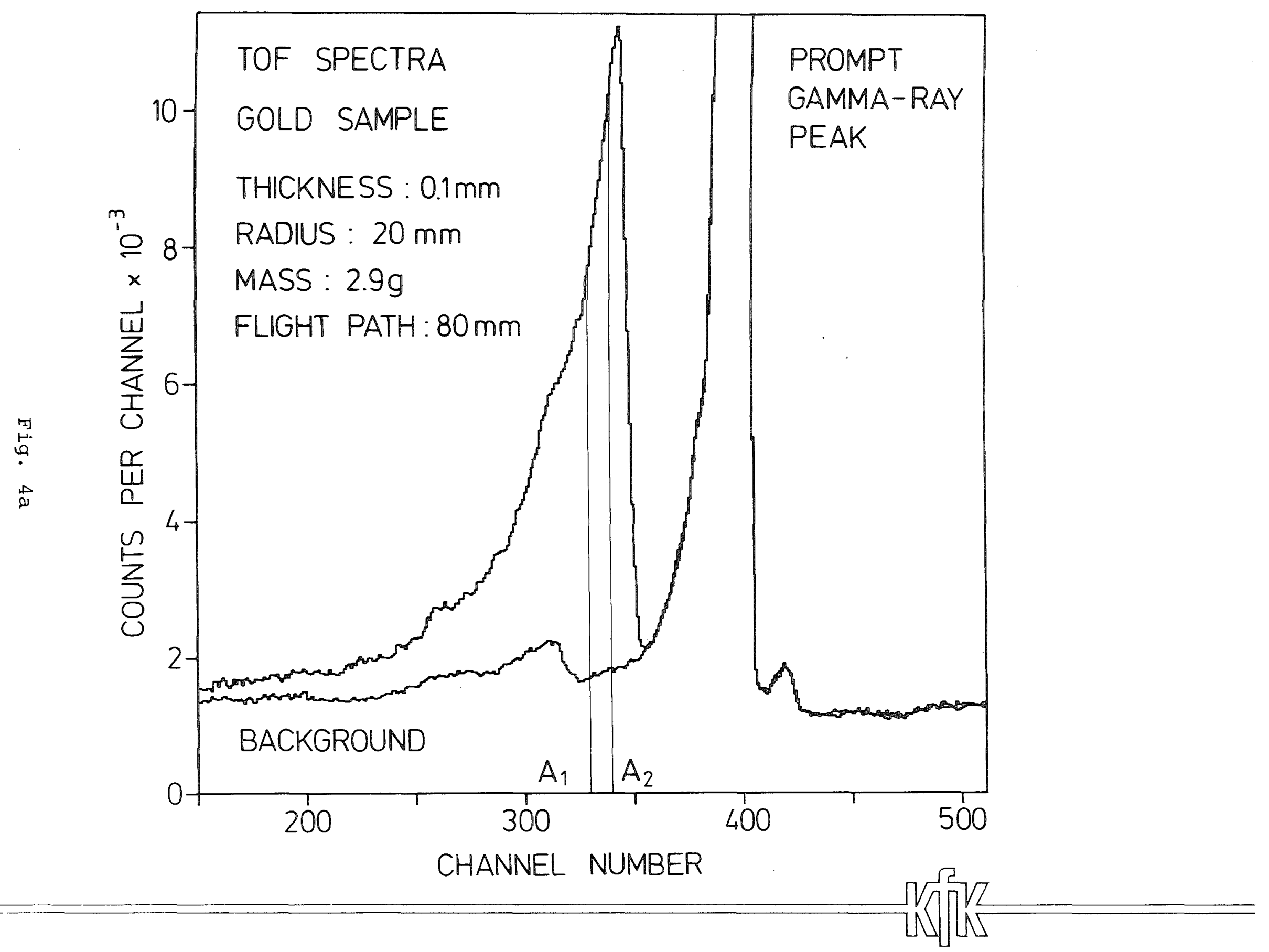



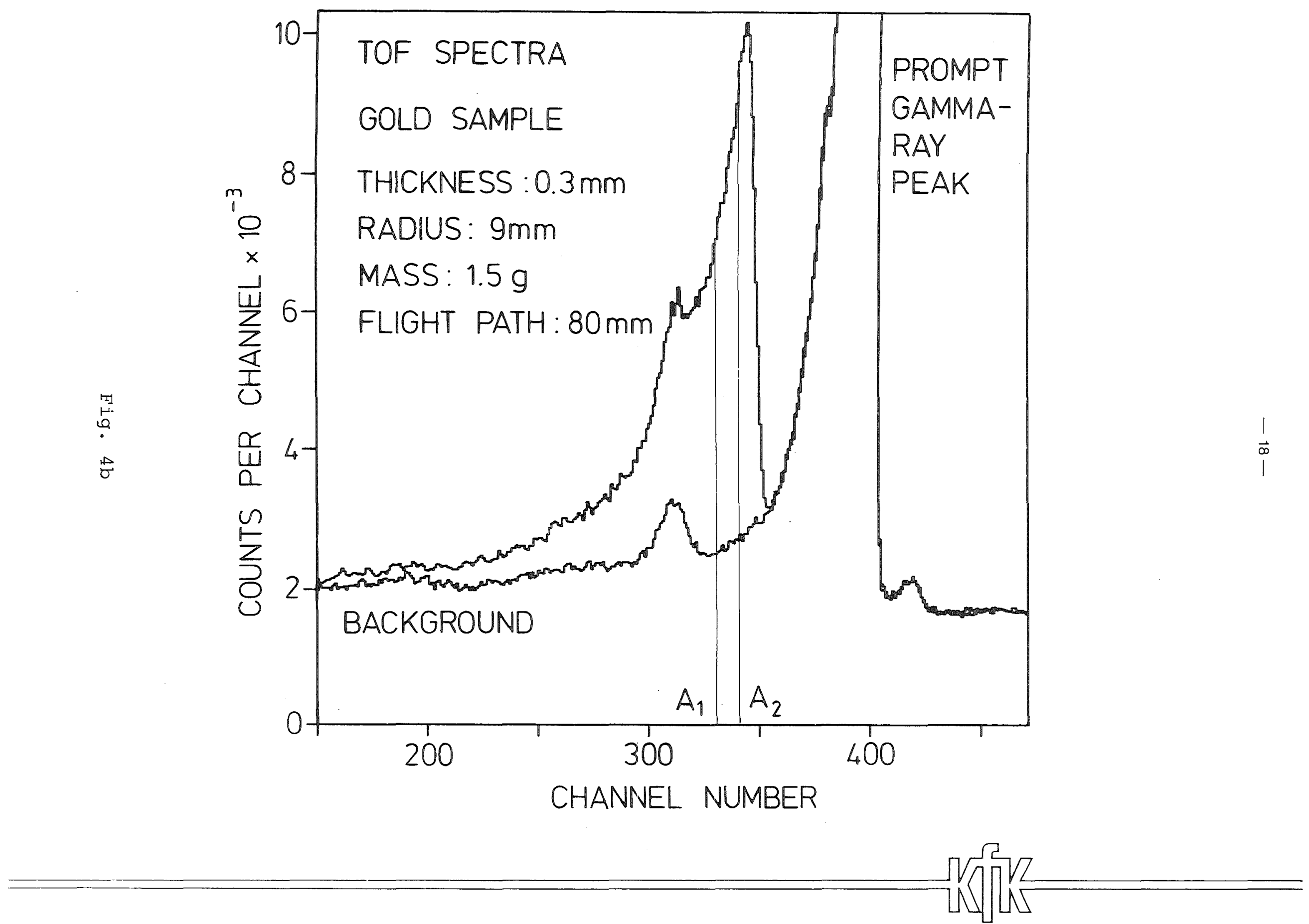


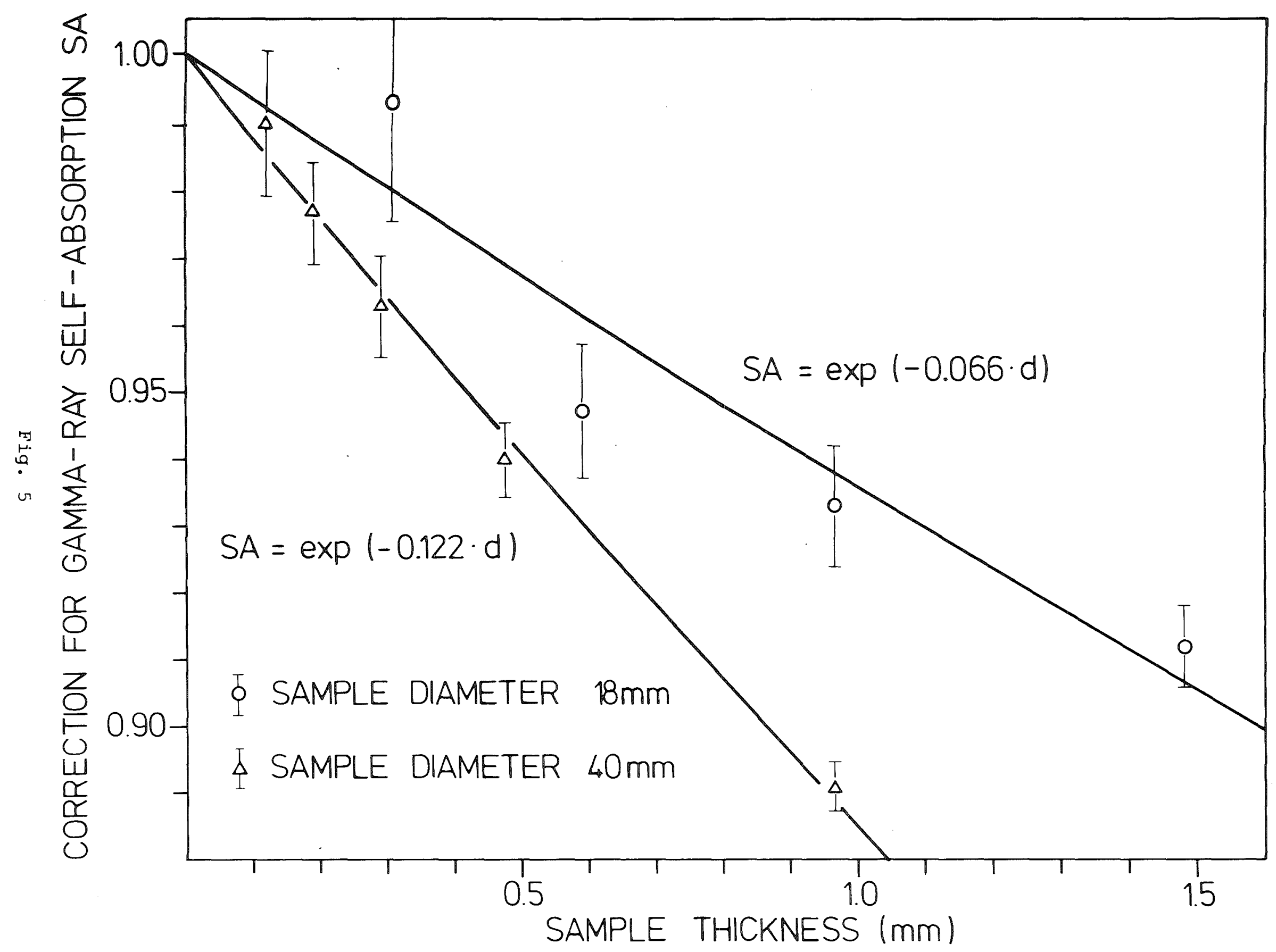




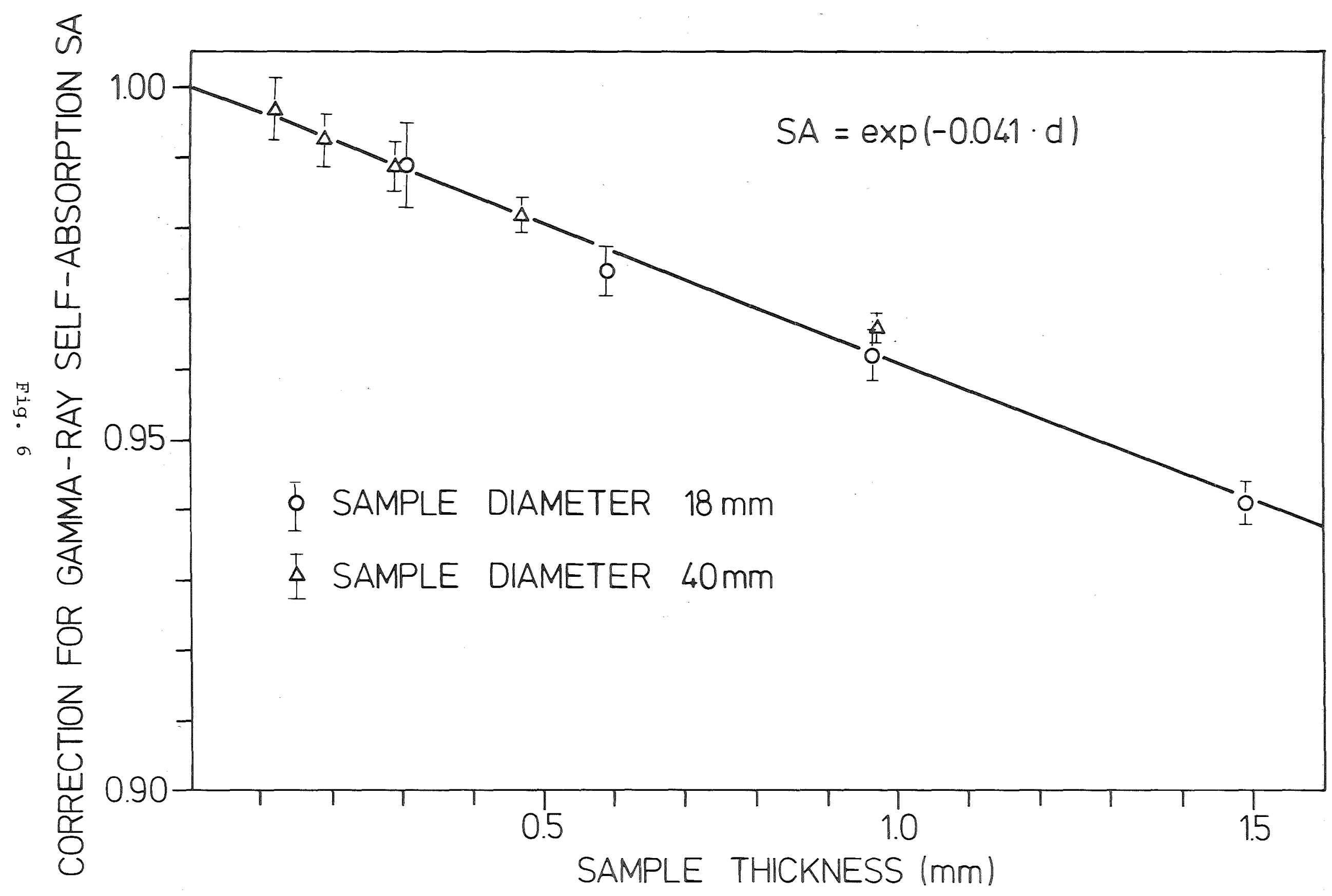

